\title{
Potential advantages of using compressorless combined cycles in power engineering
}

\author{
Mikhail Sinkevich ${ }^{1,2}$, Yuriy Borisov ${ }^{1,3}$, Anatoliy Kosoy ${ }^{1,4}$, and Eldar Ramazanov ${ }^{2}$ \\ ${ }^{1}$ Joint Institute for High Temperatures of the Russian Academy of Sciences, Izhorskaya St., Bldg. 13, Block 2, Moscow, Russia \\ ${ }^{2}$ Peoples' Friendship University of Russia (RUDN University), Miklukho-Maklaya str., Bldg. 6, Moscow, Russia \\ ${ }^{3}$ Bauman Moscow State Technical University, 2nd Baumanskaya St., Bldg. 5, Block 1, Moscow, Russia \\ ${ }^{4}$ Moscow Power Engineering Institute, Krasnokazarmennaya str., Bldg. 14, Moscow, Russia
}

\begin{abstract}
Attention of humanity is being increasingly focused on prevention of anthropogenic emissions of greenhouse gases, including $\mathrm{CO} 2$ [1]. One of the main contributions to $\mathrm{CO} 2$ emissions is associated with the production of electric and thermal energy. Despite great efforts, aimed at developing renewable energy technologies, fossil fuels will dominate in this area of human activity for a very long time. Therefore, the capture of $\mathrm{CO} 2$, formed during the combustion of fossil fuels, is of particular importance. If air is used as a fuel oxidizer, the combustion products consist of more than $70 \%$ nitrogen. It is very difficult and expensive to separate carbon dioxide from this nitrogen. Promising solutions for carbon capture are associated with air separation and fuel combustion in pure oxygen. Recently, considerable attention has been paid to such cycles [2-4]. The gases temperature of a combustor chamber exit is regulated by the supply of $\mathrm{CO} 2$ and $\mathrm{H} 2 \mathrm{O}$ to a combustion zone. In this case, a spent working fluid is almost entirely composed of a mixture of carbon dioxide and water vapor, which is easily divided into water and pure carbon dioxide. One of the options for such solutions involves a pressure increase for all components of the working fluid before injection them into a combustion chamber in a liquid phase by pumping equipment [5]. Thermodynamic cycles, in which a pressure of the working fluid is increased in the liquid phase by pumping equipment (without a compressor), can be called compressorless.
\end{abstract}

\section{Introduction}

Compressorless cycles have a number of significant advantages that will serve as prerequisites for the implementation of such cycles in the nearest future.

The main motivation for the implementation of compressorless cycles will be their environmental friendliness. Harmful emissions will be virtually eliminated. Combustion products $(\mathrm{CO} 2$ and $\mathrm{H} 2 \mathrm{O})$ will be removed from the cycle in the liquid state, for instance, water of sufficient quality to feed heating networks when water treatment is minimal, and carbon dioxide in the most convenient form for transportation.

There exist various air separation technologies, but a cryogenic rectification is most widely used. This is a sufficiently energy-intensive technological process. In addition, the main energy inputs are spent on the cold production. This cold can be utilized in the compressorless combined cycle. Such cycle suggests an increase in the pressure of all components of the working fluid in a liquid phase. If the temperature of the $\mathrm{H} 2 \mathrm{O}$ phase transition at the initial pressure substantially exceeds the ambient temperature, then the remaining components $(\mathrm{CO} 2$, fuel gas and $\mathrm{O} 2$ ) at the initial pressure have the phase transition temperature significantly lower than the ambient temperature. Condensation of these components requires cold. A significant part of the cold for these purposes can be obtained by utilizing the cold of the air separation unit. Such utilization provides a significant increase in fuel economy of the production of electric and thermal energy. Estimated evaluations showed that a power plant based on the compressorless cycle can provide an electrical efficiency of $40 \%$, taking into account energy consumption for the plant own needs. Also, $1.46 \mathrm{~kW}$ of thermal power being produced for every $1 \mathrm{~kW}$ of electric power [5]. This corresponds to a fuel utilization rate (at the lowest heat-producing capacity) of $98 \%$. Compressorless cycles promise to achieve the efficiency of electricity production no worse than the best modern combined-cycle gas turbine units (CCGT Units). In addition, when heat and electricity are produced simultaneously, not only all the heat from the lower calorific value of the fuel, but also a significant part of the heat of vaporization of the water, generated by combustion, can be used beneficially. Therefore, the coefficient of fuel utilization, referred to the lowest calorific value, may approach and even exceed the value of one. If the coefficient of fuel utilization is less than the ratio of the highest calorific value to the lowest one, the law of conservation of energy is not violated.

Compressorless cycles are semiclosed. The main advantage of open cycles is combustion inside the cycle and, as a consequence, the absence of large 
losses of exergy when heat is supplied from a hot source through the heat exchange surface. While this advantage is maintained the semiclosed cycles have almost all the advantages of closed cycles. The main of these advantages is the ability to effectively control the power of CCGT Units. The power can be changed practically without changing the efficiency of the thermodynamic cycle by preserving the determining thermodynamic parameters (ratio of expansion in the turbine, temperature of hot and cold sources) and changing the pressure in the circuit due to changes of the working fluid flow rate. Additionally, another very important advantage, associated with the ability to vary the pressure in the circuit, is the pressure increase in the circuit can significantly reduce the weight and dimensions of CCGT unit, thereby decreasing the capital costs of building the entire power plant as a whole.

Combined cycle gas turbine units, based on compressorless thermodynamic cycles, have more degrees of freedom when it is necessary to regulate the operating modes. Four components of the working fluid (fuel gas, $\mathrm{O} 2, \mathrm{CO} 2$ and $\mathrm{H} 2 \mathrm{O}$ ) are fed into the combustion chamber. Their regulation can be carried out independently. The logic of regulation of these components can fit into the following scheme:

- the fuel gas flow rate provides the required amount of generated electricity (feedback works using the following procedure: if consumers do not have enough electricity, fuel consumption increases; if there is an excess of electricity, fuel consumption decreases);

- O2 flow rate maintains the required combustion efficiency (transmitters feedback, controlling the composition of the working fluid at the combustion chamber outlet, allows to increase or decrease oxygen flow rate depending on the presence of unburned hydrocarbons or free oxygen);

- $\mathrm{CO} 2$ flow rate provides the required temperature of the working fluid at the turbine inlet (the working fluid temperature monitoring system feedback works as follows: if the temperature is high, the carbon dioxide flow rate increases; if the temperature is low, the flow rate decreases);

- H2O flow rate keeps up the amount of generated thermal energy (feedback works in the following ways: if consumers lack thermal energy, $\mathrm{H} 2 \mathrm{O}$ consumption increases; if there is an excess of thermal energy, consumption decreases).

In addition to the opportunity to provide required flow rates of the certain components of the working fluid, it is possible to control the pressure at the turbine outlet. For instance, the pressure of the working fluid at the turbine outlet can be increased or decreased by changing the condensation modes of $\mathrm{H} 2 \mathrm{O}$ and $\mathrm{CO} 2$. At the same time, the expansion efficiency of the turbine will remain constant or change in the optimal range. Thus, all parameters, determining the fuel efficiency of the thermodynamic cycle, can be kept in the optimal range in almost all operating modes and to provide as high efficiency as possible regardless of the operating mode. In this case, the temperature regime of operation of almost all parts of the CCGT Unit, which implements the compressorless cycle, will be constant. The constancy of the temperature regime solves a number of very important problems associated with thermal expansions, causing the thermal stresses in the structural elements.

\section{Analysis of parameters for compressorless cycles}

The ratio of heat and electricity production in the compressorless thermodynamic cycle is mainly determined by the ratio of $\mathrm{CO} 2$ and $\mathrm{H} 2 \mathrm{O}$, supplied to the combustion chamber. The estimation calculations with different ratios of $\mathrm{CO} 2$ and $\mathrm{H} 2 \mathrm{O}$ were conducted for the same conceptual scheme and basic parameters where an electrical efficiency of $40 \%$ was shown in the production of $1.46 \mathrm{~kW}$ of thermal power for every $1 \mathrm{~kW}$ of electric power [5]. The dependence of electric efficiency, coefficient of fuel utilization (CFU) and the ratio of total power output (the sum of thermal and electric power) to electric power, supplied to the network, from the flow rate ratio of $\mathrm{CO} 2$ to $\mathrm{H} 2 \mathrm{O}$ (logarithmic scale) is shown on Fig. 1.

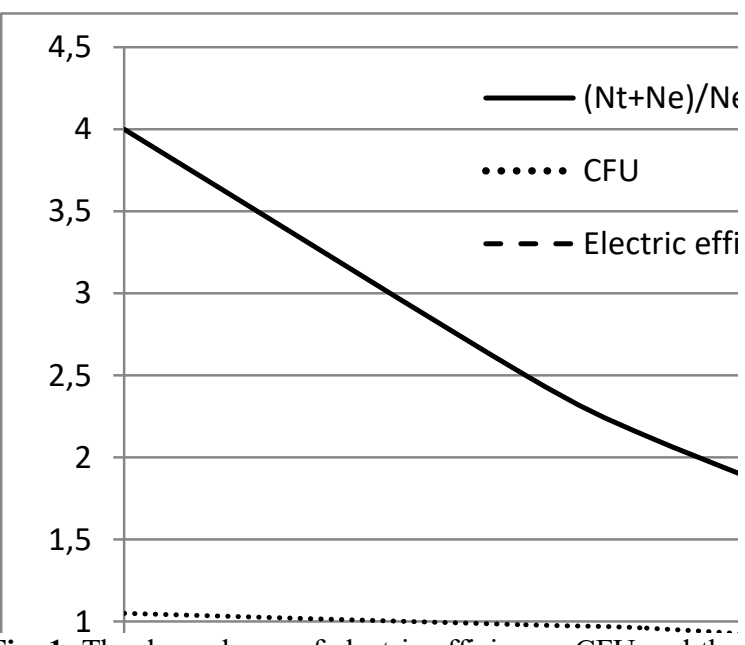

Fig. 1. The dependence of electric efficiency, CFU and the ratio of total power output to electric power from the flow rate ratio of $\mathrm{CO} 2$ to $\mathrm{H} 2 \mathrm{O}$ (logarithmic scale).

The coefficient of fuel utilization and electric efficiency are related to the lower calorific value. The total amount of energy generation is four times greater than the amount of electric energy with minimal flow rate ratio of $\mathrm{CO} 2$ to $\mathrm{H} 2 \mathrm{O}$. This ratio is very close to the ratio of the installed heat and electric power of most thermal power plants. Usually, this ratio of installed capacities is achieved due to peak-load boiler houses. These boiler houses operate a few hours a year, but they require significant capital expenditures during the construction, and constant expenses for their maintenance. Such a wide range of regulation of the ratio of generated capacities in CCGT unit, based on compressorless cycles, allows to eliminate the peak-load boiler houses. 
The electric efficiency of the compressorless CCGT unit decreases with an increase in the production of thermal energy. Nevertheless, this decrease does not indicate a reduction in profitability. The main criterion of profitability is coefficient of fuel utilization since it is close to one with almost all ratios of thermal and electrical loads (almost all of the fuel energy, traditionally considered available, is converted into a useful product). CFU even exceeds a value of one at maximum thermal loads. This is due to the part of water condensation heat, formed as a result of fuel combustion, which is traditionally not referred to available energy, in this case turns into useful heat. If the heat demand is small, for example, only hot water supply in the summertime, then it is advisable to increase the flow rate ratio of $\mathrm{CO} 2$ to $\mathrm{H} 2 \mathrm{O}$ to the maximum. In this case, heat generation is minimized (thermal power is half of electric power), CFU is slightly reduced (approximately to 0.87 ), but the electric efficiency, taking into account the own needs of the thermal power plant, rises to 0.56 .

When heat is not required and only electricity is generated, electric efficiency becomes a measure of efficient performance. In such modes it is also advisable to increase the flow rate ratio of $\mathrm{CO} 2$ to $\mathrm{H} 2 \mathrm{O}$ to the maximum. If heat is not produced, then the coefficient of fuel utilization coincides in meaning and size with electric efficiency. Given the fact that in the absence of a heat load, there is no energy consumption for providing heat to the consumer (transportation of heat transfer fluids), which is part of the own needs of the thermal power plant. Therefore, the electric efficiency is slightly higher in the production of only electricity than in the joint production.

The analysis of the compressorless thermodynamic cycles advantages is evaluative. The performed benefit assessment of compressorless combined cycles has shown a real prospect for their practical implementation. In order to create a scientific basis for the design of installations, based on compressorless combined cycles, it is planned to continue work in the following areas: development of program codes for research and optimization of compressorless combined cycles; search for optimal circuit designs for power plants that implement work on the basis of compressorless combined cycle; optimization of compressorless combined cycles parameters.

\section{Conclusion}

Current trends to reduce $\mathrm{CO} 2$ emissions, associated with climate change, bring to one of the first places technologies with air separation and using pure oxygen as a fuel oxidizing agent, since these technologies make it possible to completely capture $\mathrm{CO} 2$ from combustion products. Compressorless combined cycles are one of the perspective directions of such technologies. There are a number of prerequisites that allow to talk about the practical implementation of such cycles in the near future.
Air separation is a fairly energy-intensive process. The main energy costs for air separation are associated with the production of cold when using the cryogenic rectification process. This cold is utilized in the compressorless combined cycle in condensation processes of other components of the working fluid, thereby significantly increasing fuel efficiency. Estimated calculations show that CFU is close to value of one in the combined production of heat and electricity, taking into account energy consumption for own needs. When producing only electricity, electric efficiency, taking into consideration own needs, can reach $58 \%$.

The main advantage of open cycles is maintenance of the high temperature of the hot source that compressorless cycles also have along with almost all the advantages of closed cycles. The main of these advantages is the ability to effectively control the power of CCGT unit. Therefore, while maintaining the determining thermodynamic parameters and varying the pressure in the circuit, the power of this unit is changed almost without varying the electric efficiency of the thermodynamic cycle due to a change in the flow rate of the working fluid.

Another very important positive quality of compressorless thermodynamic cycles is a possibility to independently control the production of thermal and electric energy in a CCGT unit, implemented by such cycles. By changing the ratio of the working fluid components, supplied to the combustion chamber, it is possible with constant electric power to change the thermal power. In that case, the maximum thermal power will exceed the minimum one more than six times and CFU will be close enough to the value of one in the full range. This range of the thermal loads regulation provides the possibility of year-round supply of heat without additional peakload boiler houses. In addition, it allows to work effectively in the summer, providing only a hot water supply, and in the winter, covering all the needs of heat on the coldest days. The rejection of additional peak-load boiler houses will reduce both capital expenditures to build and operating costs.

Conducted analysis of compressorless combined cycle is evaluative, but even such rough estimates indicate the actuality of work in this direction. In order to create a scientific basis for the design of installations, based on compressorless combined cycles, it is planned to continue work in the following areas: development of program codes for research and optimization of compressorless combined cycles; search for optimal circuit designs for power plants that implement work on the basis of compressorless combined cycle; optimization of compressorless combined cycles parameters.

\section{Acknowledgment}

The research was financially supported by the Russian Science Foundation (project № 19-1900558). 


\section{List of references}

1. Climate Change 2014: Synthesis Report. Geneva, Switzerland: IPCC, 2014.

2. Oxy-fuel gas turbine, gas generator and reheat combustor technology development and demonstration / R. Anderson, F. Viteri, R. Hollis et. al. //ASME Paper GT2010- 23001, ASME Turbo Expo. 2010.

3. Yang H. J., Kang D.W., Ahn J.H., Kim T.S. Evaluation of design performance of the semiclosed oxy-fuel combustion combined cycle //Journal of Engineering for Gas Turbines and Power. 2012. Vol. 134. No 11. P. 111702.

4. High efficiency and low cost of electricity generation from fossil fuels while eliminating atmospheric emissions, including carbon dioxide / R.J. Allam, M.R. Palmer, G.W. Brown et. al. // Energy Procedia. 2013. Vol. 37. P. 1135- 1149.

5. The Conceptual Process Arrangement of a Steam-Gas Power Plant with Fully Capturing Carbon Dioxide from Combustion Products / A. S. Kosoi, Yu. A. Zeigarnik, O. S. Popel, M. V. Sinkevich, S. P. Filippov, V. Ya. Shterenberg // Thermal Engineering, 2018, Vol. 65, No. 9, pp. 597-605. DOI: 10.1134/S0040601518090045 